\title{
Research Paper: Relationship of Academic Vital- ity, Academic Self-efficacy, and Metacognitive Skills With Lifelong Learning Concerning Mediating Role of Study Approaches
}

\author{
Marzieh Khamisabadi $^{1}$ (D), Seyed Reza Mirmehdi ${ }^{1}$ (D), Ali Reza Merati ${ }^{1^{*}}$ (i) \\ 1. Department of Educational Sciences and Psychology, Payame Noor University, Tehran, Iran
}

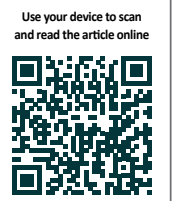

Citation Khamisabadi M, Mirmehdi SR, Meraati AR. Relationship of Academic Vitality, Academic Self-efficacy, and Metacognitive Skills With Lifelong Learning Concerning Mediating Role of Study Approaches. Journal of Health Research. 2021; 11(1):1-10. http://dx.doi.org/10.32598/JRH.11.1.1202.4

http://dx.doi.org/10.32598/JRH.11.1.1202.4

\section{c) (1) (9)}

Article info:

Received: 06 Oct 2017

Accepted: 04 Apr 2019

Publish: 01 Feb 2021

\section{Keywords:}

Learning, Vitality, Selfefficacy, Metacognitive

\section{A B S T RACT}

Background: Nowadays, learning is one of the most important factors in the lives of human beings. Lifelong learning and its effective variables are the topics of discussion in the contemporary era. In this regard, the present study was done to investigate the relationship between academic vitality, academic self-efficacy, and metacognitive skills, and lifelong learning concerning the mediating role of study approaches among students of Payame Noor University, Kangavar branch in the academic year 2016-2017.

Methods: A random sampling method was used to select the participants. The sample size was determined to be 168 students. The required data were collected using the Academic Vitality Inventory, the Self-efficacy Scale, the Metacognition Questionnaire-30 (MCQ-30), Approaches and Study Skills Inventory for Students (ASSIST), and the Lifelong Learning Inventory. In total, 128 questionnaires were completely filled out and collected.

Results: The results were analyzed using the Pearson Correlation and Structural Equation Modeling (SEM) using PLS and SPSS V. 20 software. The results showed that the model suitably fitted the data. The main research hypothesis was accepted at the 0.002 significance level. Academic self-efficacy, study approaches and skills, and metacognitive skills were directly correlated with lifelong learning $(\mathrm{r}=0.436, \mathrm{P}=0.001)$.

Conclusion: Education and emphasis on study give incentives for lifelong learning. In a normal situation, no relationship was found between lifelong learning and other factors.

\footnotetext{
* Corresponding Author:

Ali Reza Merati, PhD.

Address: Department of Educational Sciences and Psychology, Payame Noor University, Tehran, Iran.

Phone: +98 (912) 0201544

E-mail:alirezamerati@pnu.ac.ir
} 


\section{Introduction}

A

brief history of humankind shows that learning and learning styles are certainly the most important factors in human life. Learning can be defined as a relatively stable change in behavior, information, and thinking skills acquired through experience [1]. Learning is currently considered a lifelong approach due to several reasons [2]. Limited resources of information were accumulated in the formal education system in the past. Reliance on these sources is not logical for teaching in necessary cases in the future given the broad changes in the world in the current era. All of these factors necessarily show that learning cannot be limited to a certain period of individual life. The consequences of this approach led to the formation of a new paradigm relying on continuous learning throughout the individual life called lifelong learning. According to this approach, an individual is always engaged in learning. People continuously increase their knowledge, skills, and interests throughout their lives in lifelong learning. Other common reasons for the concept of lifelong learning include the rapid increase in changes in the lifespan of individuals in different societies at present compared with the past. These changes led to the explosion of knowledge and transient information [3]. This perspective is inevitable in the present era. As a result, the illiterates in the future will not be those who cannot read and write, but those who cannot learn, unlearn, and relearn [4].

Richardson believes that lifelong learning has three main points. First, the whole education system should focus on the acceptance of lifelong learning [1]. Second, organizations, institutions, and enterprises also need lifelong learning trends in addition to education systems. Third, individuals are responsible for a learning management system. Studying is one of the most important learning styles that help learners to learn many materials. Undoubtedly, studying is one of the most important and basic human transcendental activities with a special role in human life that leads to the development of culture and civilization in society. Thereby, pedagogical scholars and educators have defined certain conditions for classic and institutional learning, including individual talents and capabilities, motivation and interest, educational facilities, and learning and studying methods [5].

Learning methods and styles of studying generally refers to the right, organized, and coherent style of studying [6]. Learning and studying skills are similar to cognitive and metacognitive strategies as discussed in the information processing theory in cognitive psychology.
These strategies can be learned and taught [7]. Proper and timely use of strategies improves the understanding of the course content and academic achievement of the students. Studying can be easier, faster, and lovelier using these strategies. A systematic and authentic studying method can eliminate many academic problems. Studies have shown that an authentic study style can facilitate academic success. There are two surface and deep study and learning strategies. PQ4R learning strategy is derived from the first six letters of six-step learning as a preview, question, read, reflect, recite, and review [8].

Various components and variables are also effective in learning. Academic vitality is one of these variables. This variable is reflected in an academic period with cognitive and social changes [9]. Academic vitality refers to a positive, constructive, and adaptive response to a variety of challenges and obstacles faced in everyday and normal situations [10]. This variable is derived from positive psychology [11] that enables students to successfully overcome academic barriers and challenges, such as poor grades, test pressure, and difficult assignments in the course of academic career and school. Richardson and Wolfe [12] believe that vitality is the energy that arises from the individual and stems from intrinsic sources rather than the threats of an external source. In other words, vitality represents a lively nature that is not forced or stimulated. An individual is inherently vivid [13]. The individuals will not be bored with doing assignments and disappointed with the school if they do these tasks spontaneously. Academic vitality refers to a positive and constructive response to several challenges and barriers experienced in an ongoing and continuous academic course [14].

Lifelong learning should be defined with some variables because it is an ongoing trend throughout life. Self-efficacy may be one of those variables. Bandura introduced self-efficacy as a key component in his theory and emphasized the role of personal beliefs in individual capabilities to do specific activities in a certain situation. The theoretical background of this concept suggests that individuals acquire self-efficacy through physical activities and interaction with family members early in childhood and develop self-efficacy through relationships with peers and school experiences later in adulthood. In this regard, self-efficacy can certainly affect internal processes and raise a purposeful and productive individual. Cognitive and metacognitive strategies contribute to learning and reciting. Although these strategies can be learned, some learners cannot learn them and need educators to teach these strategies [15]. The broader the variety of the strategies properly used by the students, the more the 
success in problem-solving, reading, comprehension, and information reciting skills [16]. Learners who are aware of their own learning and studying methods can select and do certain activities to improve these methods and increase the quality and quantity of their learning more than those who are not aware of their learning styles. They consciously fit certain strategies to certain goals using their metacognitive knowledge [17]. Although they do not distinguish cognition from metacognition, they believe that cognition involves thinking while metacognition involves thinking about the thinking process.

The term cognition refers to the intrinsic processes or information processing methods, i.e. methods used to preview, recognize, and encrypt information and store them in memory to be recalled whenever necessary. Cognition simply refers to understanding. From the perspective of psychology, cognition is defined as thinking and learning styles and data organization, storage, and application [18]. Dori and Murphy defined cognitive strategies as the methods, through which people can manage their learning process and recall and think about what they have learned [2]. Hendry described cognitive strategies as problem-solving schemes or methods [19]. He believes that cognitive strategies are explorations of information processing. Individuals in the information acquisition process need to control and organize external stimuli, scientific and creative activities using cognitive strategies [20]. Cognition involves the acquisition, processing, storage, and transfer of information while metacognition is an activity that encompasses and supervises the actions involved in the four above-mentioned components of cognition [21]. Gourchian found that using metacognitive strategies is related to reading and comprehension capabilities and learning speed [22]. Ebrahimi Ghavamabadi also reported that teaching these strategies is positively related not only to reading comprehension and learning speed but also to positive selfconcept, planning, and problem-solving [23]. Abdous also assessed that teaching metacognitive strategies has a positive impact on creativity [24].

Accordingly, the present study was done to investigate the relationship between academic vitality, academic selfefficacy, and metacognitive skills and lifelong learning through the mediating role of study approaches in order to better understand and comprehend these variables and provide long-lasting lifelong learning. For this purpose, learning and subsequent lifelong learning are prerequisites of the modern world of information intelligence. Many studies have addressed different aspects of this subject. In this paper, a model is given to determine the relationship between these variables and lifelong learning.

\section{Methods}

The current descriptive-correlational study was conducted on 810 students of Payame Noor University in Kangavar (380 males and 430 females) in the academic year 2016-2017. A simple random sampling method was used to select 162 individuals according to the Morgan table. Accordingly, 162 questionnaires were distributed to the participants. Later, 128 completely filled out questionnaires were collected and analyzed. Measurement tools are given as follows:

Academic Vitality Inventory: This tool was developed by Hossein Jari and Dehghanizadeh based on the Academic Vitality Scale developed by Martin and Marsh [11]. The scale consists of 41 items. However, the inventory covers nine single-component items. The items are scored based on a five-point Likert scale (from totally disagree $=1$ to totally agree $=5$ ). A higher score in this test reflects higher academic vitality. The minimum score is 9 and the maximum score is 45. Dehghanizadeh and Hossein Jari estimated the reliability of this scale as 0.8 and the test-retest reliability as 0.73 . Moradi and Cheraghi assessed the reliability of the scale using Cronbach's alpha $(\alpha=0.7)$.

Academic Self-efficacy: This scale was developed by Patrick, Hicks, and Ryan. This scale consists of five items that reflect students' perceptions of their competence in doing assignments. This scale is a self-report tool. The items are scored based on a five-point Likert scale (totally disagree $=1$, disagree $=2$, no idea $=3$, agree $=4$, and totally agree $=5$ ). The reliability of this scale was assessed by Miguel et al. using Cronbach's alpha $(\alpha=0.78)$. Hashemi Sheikh Shabani (2001) assessed the reliability of this scale using Cronbach's alpha and Spearman-Brown split-half method, and the reliability coefficients were reported as 0.65 and 0.59 , respectively [8]. Haji Yakhchali (2001) also assessed the reliability of the academic selfefficacy scale using Cronbach's alpha and the split-half method, and the reliability coefficients were calculated as 0.73 and 0.66 , respectively [14]. This reflected the suitable and acceptable reliability of the scale. Cronbach's alpha was also used to assess the reliability of the academic self-efficacy scale in this study $(\alpha=0.74)$.

Metacognitive Skills: A short form of the Metacognition Questionnaire-30 (MCQ-30) was used to collect data on metacognitive skills. This self-report questionnaire consists of 30 items and was developed by Wales. The questionnaire measures individual beliefs about their thinking. The items were scored based on a fourpoint Likert scale (disagree $=1$, somehow agree $=2$, rela- 
tively agree $=3$, and completely agree $=4$ ). The questionnaire has five subscales. Questions 1, 7, 10, 19, 23, and 28 assess positive beliefs about worry, questions $2,4,9$, 11,15 , and 21 assess negative beliefs about worry, questions $8,14,17,24,26$, and 29 assess cognitive restructuring for the lack of confidence, questions $6,13,20$, 22,25 , and 27 assess the need to control thoughts, and questions $3,5,12,16,18$, and 30 assess metacognitive process and cognitive self-awareness. Wales, Carthage, and Hatton quoted Richardson and used Cronbach's alpha to assess the reliability of the scale and its subscales. The range of alphas for the scale and its subscales varied from 0.93 to 0.76 . The test-retest reliability coefficient of the scale was calculated as 0.75 and varied from 0.59 to 0.87 for the subscales. Cronbach's alpha of the scale was reported as 0.91 in an Iranian sample. The alphas for the subscales of uncontrollability, positive beliefs, cognitive beliefs, cognitive confidence, and the need to control thoughts were reported as $0.87,0.86,0.81,0.8$, and 0.71 , respectively, in this sample [25].

Study strategies: The inventory of approaches and study skills for students was used to collect data on the study styles of the students. The inventory was developed by McCune and Antitheist. It is the final version of a questionnaire used to investigate the study approaches of students. Antitheist et al. studied the validity and reliability of the inventory. The reliability of subscales of surface and deep learning styles varied from 0.53 to 0.76 . The reliability of subscales of deep and surface approaches varied from 0.84 to 0.8 . The inventory has three sections. Study approaches are assessed in the second section consisting of 32 items. Sixteen items were used to assess the subscale of deep approaches and 16 items to assess the subscale of surface approaches. A single score is given to every four subscales of deep and surface learning approaches. The sum of these scores gives the total score of each participant in deep and surface approaches.

The lifelong learning questionnaire was developed by Utzel et al. The scale consists of 14 items. A four-point Likert scale is used to score the items (from totally agree to totally disagree). The score of each item varies from 1 to 4 . Lifelong learning is measured using items, such as "continuous learning throughout life (lifelong learning) is a professional responsibility of all students". The components of this scale are motivation and learningrelated beliefs $(11,9,8,7,3,2,1)$, information seeking skills $(14,10,6,5)$, and attention to individual competence. The questionnaire items were scored based on a four-point Likert scale (totally disagree $=1$, disagree $=2$, agree $=3$, and totally agree $=4$ ). The sum of scores is calculated and used for analysis. The scores are interpreted based on the below table. The scores are given for one questionnaire and the scores should be multiplied by 10 in the case of 10 questionnaires. Minimum score $=$ the number of questionnaire items $\times 1$. Maximum score; 56 . Average grades score: 28. Minimum score: 14 .

The sum of scores of the 14 items of the lifelong learning questionnaire was calculated. The minimum score was 14 and the maximum score was 56 . The score was 14-18 in low lifelong learning, 18-36 in moderate lifelong learning, and $>36$ in high lifelong learning. Tagipour et al. [23] confirmed the validity of the questionnaire based on the opinions of professors and experts. They also assessed the reliability of the questionnaire using Cronbach's alpha $(\alpha=0.78)$.

The measurement tools were prepared. The head of the university approved the research and gave the necessary orders to carry out the tests. The individuals were evaluated in separate groups. Each group consisted of 30 individuals. Prior to the test, the students were ensured that their personal information would not be needed in this research. This was solely a student project. The collected data were kept confidential. The students were asked to give accurate information and cooperate with the author to fill out the questionnaires. Break time was given after the distribution and completion of each questionnaire given a large number of questionnaires. In the end, the students were well-received by the testers and suitable food and drinks were available in the reception area. The collected data were sorted and analyzed.

The data were analyzed using descriptive statistics of Pearson correlation, path analysis, and regression analysis by SPSS v. 20 and Smart-PLS. Descriptive statistics of the respondents' age: mean: 29/90; median: 29; mode: 26 and standard deviation: 5/72; minimum: 20; maximum: 48; and sum: 3828.

\section{Results}

Convergent and divergent validity were used to determine the validity of the data collection tools. Convergent validity refers to the moderate correlation of the components of each tool. Fornell and Larcher quoted Mashhadi et al. [10] and defined convergent as the average Variance Extracted (AVE) value of $>0.5$. Divergent validity is defined as root $\mathrm{AVE}>$ correlation of that tool with other tools [6]. Cronbach's alpha and composite reliability coefficients were used to determine the reliability of the questionnaire. Alphas were above 0.7 for all variables. Unlike Cronbach's alpha that implicitly assumes that each index has an identical weight, the com- 
Table 1. Convergent validity and reliability of the measurement tools

\begin{tabular}{|c|c|c|c|c|}
\hline Research Variables & $\begin{array}{l}\text { Extracted Mean- } \\
\text { variance Coefficient }\end{array}$ & Factor Loads & $\begin{array}{l}\text { Composite Reliability Coefficient } \\
\text { (cr) pc >0/7 }\end{array}$ & $\begin{array}{l}\text { Cronbach's Alpha } \\
\text { Reliability Index }\end{array}$ \\
\hline Academic vitality & 0.58 & - & 0.82 & 0.84 \\
\hline Academic self-efficacy & 0.73 & - & 0.71 & 0.78 \\
\hline Lifelong learning & 0.85 & - & 0.73 & 0.76 \\
\hline Metacognitive skills & 0.78 & - & 0.81 & 0.85 \\
\hline Unreliability & - & 11.774 & - & - \\
\hline Negative beliefs & - & 14.324 & - & - \\
\hline Positive beliefs & - & 6.932 & - & - \\
\hline Biosphere awareness & - & 12.08 & - & - \\
\hline Need to control & - & 9.156 & - & - \\
\hline Study approaches & 0.91 & - & 0.68 & 0.76 \\
\hline Surface approach & - & 5.748 & - & - \\
\hline Deep approach & - & 13.435 & - & - \\
\hline
\end{tabular}

IRA

posite reliability depends on the actual loading factors of each component. Therefore, composite reliability is more suitable for the assessment of reliability.

According to the information and the outputs of SMART-PLS given in Tables 1 and 2, the measurement tool had acceptable content, convergent, and divergent validity, loading factors, composite reliability, and Cronbach's alpha. Tables 2 and 3 show the results of the assessment of reliability and validity in detail.

Two types of statistical tests are used in SMART-PLS: A. A measurement model that measures the validity of the measurement tools; and B. Structural modeling that tests the hypotheses and the effect of latent variables on each other. The structural equation model was used to analyze and measure the model used in this study. Structural equation modeling is a statistical model for investigating the linear relationships between the latent variables (unobserved variables) and manifest variables (observed variables). In other words, the SEM is a powerful statistical technique that combines the measurement model (confirmatory factor analysis) and the structural model (regression or path analysis) with a simultaneous test. Through these techniques, scholars can reject hypothetical structures (models) or confirm



Figure 1. The conceptual model of the research 
Table 2. Solidarity matrix and divergent narrative review

\begin{tabular}{ccccccc}
\hline Variables & Academic Vitality & $\begin{array}{c}\text { Study Ap- } \\
\text { proaches }\end{array}$ & $\begin{array}{c}\text { Academic } \\
\text { Self-efficacy }\end{array}$ & $\begin{array}{c}\text { Metacognitive } \\
\text { Skills }\end{array}$ & Lifelong Learning & Root AVE \\
\hline Academic self-efficacy & 1 & & & & 0.85 \\
\hline Study approaches & 0.394 & 1 & & & 0.95 \\
\hline Academic vitality & -0.108 & -0.315 & 1 & 1 & 0.76 \\
\hline Metacognitive skills & 0.055 & -0.220 & 0.045 & -0.164 & 1 & 0.23 \\
\hline Lifelong learning & -0.015 & -0.070 & -0.006 & & 0.12 \\
\hline
\end{tabular}

the fitness of the model to data. Smart-PLS was used in this research for data analysis. This software analyzes structural equation models with multiple variables and direct, indirect, and interactive effects. This is suitable for testing the moderating effects.

The t-value shows the significance of the effect of the variables in Smart-PLS. If the t-value is more than 1.96, the effect is significant and positive. If the t-value is less than 1.96, the effect is insignificant but negative. If the $\mathrm{t}$-value is between +1.96 and -1.96 , the effect is insignificant. The path coefficients of $>0.6$ show a strong relationship between the two variables. There was a moderate relationship between the two variables concerning the path coefficients of 0.3 to 0.6 . The path coefficients of $<0.3$ show a weak relationship between the two variables. Tables 2 and 3 present the results of testing the hypotheses. Figures 1 and 2 show the acceptance of the main hypothesis. Thereby, the relationship of academic vitality, academic self-efficacy, and cognitive skills with study strategies was significant with the mediating role of study approaches. The model suitably fitted the data.

\section{Discussion}

The present study was done to investigate the relationship between academic vitality, academic self-efficacy, and metacognitive skills, and lifelong learning through the mediating role of study approaches. The statistical population consisted of male and female students of Kangavar Payame Noor University. The required data were collected using five standardized questionnaires. Pearson correlation descriptive statistics, and structural equations were used to analyze the statistical data. The results showed no significant correlation between academic vitality and lifelong learning concerning the mediating role of study approaches. Therefore, the null hypothesis was accepted and the research hypothesis was rejected. The insignificance of the relationship between academic vitality and lifelong learning can be due to per- suasion or external stimuli. Academic vitality cannot be regarded as an intrinsic trait. In other words, incentives and competition provide an opportunity for academic vitality. If these two factors are not present, academic vitality no longer exists. On the other hand, academic vitality will disappear after a successful situation (i.e. successful career). Thereby, the individual is no longer motivated to acquire knowledge and loses incentive for more learning (lifelong learning).

Pearson correlation descriptive statistics and structural equations were used to test the second hypothesis. The results showed no significant relationship between academic self-efficacy and lifelong learning. As a result, the null hypothesis was accepted and the second hypothesis was rejected. As mentioned earlier, self-efficacy refers to the individual's perception of the capability to do an activity, deal with its outcome, and control a situation. In this regard, an individual's perception and state are transient and manifest under certain circumstances. Academic success is promised in an individual with selfefficacy but lifelong learning seems rare under the same circumstances because increasing success and growth in the modern industrial world is not possible given the increasing number of issues that should be dealt with in both career and domestic life. However, a positive significant relationship was found between academic self-efficacy and study approaches. This confirms the above-mentioned factors. Certainly, an individual manifesting self-efficacy has certain approaches to study that improves self-efficacy.

Pearson correlation descriptive statistics and path analysis were used to test the third hypothesis. The null hypothesis was rejected at a 95\% confidence level, 0.001 significance level, and comparing it with 0.05 allowed error level. As a result, there was a significant relationship between metacognitive skills and lifelong learning. Accordingly, the third hypothesis was accepted. There was a positive and direct correlation between these two variables 


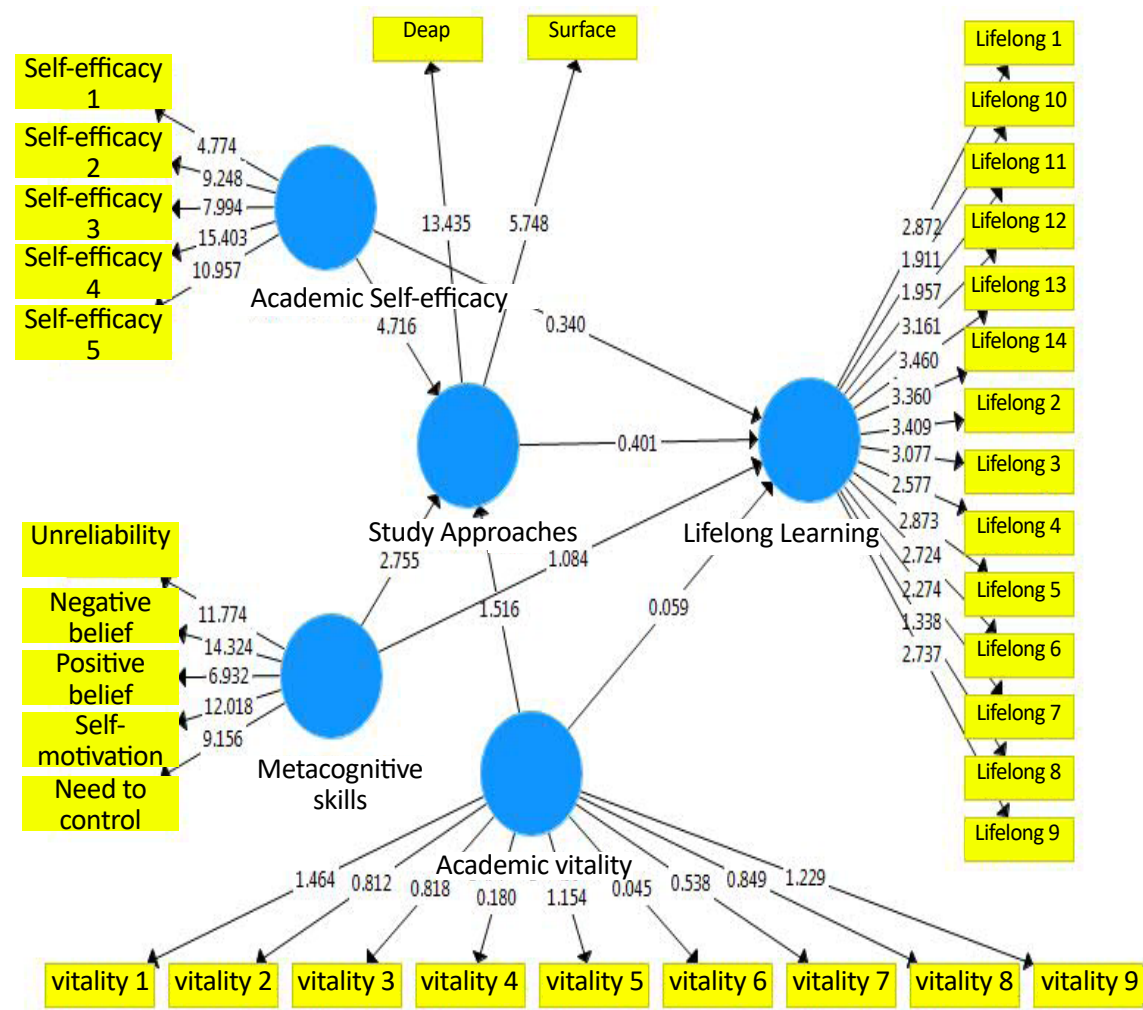

Figure 3. Model of t-test results

given the value and sign of the Pearson correlation coefficient (0.436). Therefore, the tendency to lifelong learning enhances as the students improve their metacognitive skills. The significance of the relationship between metacognitive skills and lifelong learning results from the positive reinforcement of metacognitive skills. As mentioned earlier, metacognitive strategies supervise and direct cognitive strategies. Therefore, metacognitive skills supervise and control the students' thoughts and relate to their cogni- tive tasks ${ }^{1}$. This skill creates a horizon for the individual that is independent of the environment and reinforces the surrounding individuals and definitely creates a permanent pleasant or steady-state to improve these skills.

Pearson correlation descriptive statistics and path analysis were used to test the fourth hypothesis. The results showed that the null hypothesis was rejected and the research hypothesis was accepted. The high correla-

1. Metacognitive skills are defined as control and supervision of thoughts in order to do cognitive tasks.

Table 3. Summary of the results of hypothesis testing by structural equation modeling

\begin{tabular}{ccccc}
\hline Effect Level & Sig. & t-test Value & Coefficient & Routes \\
\hline Strong & Significant & 4.71 & 0.355 & Academic self-efficacy - Study approaches \\
Weak & Not significant & 0.340 & -0.045 & Academic self-efficacy - Lifelong learning \\
Moderate & Significant & 2.75 & -0.189 & Metacognitive skills - Study approaches \\
Moderate & Significant & 1.084 & -0.154 & Metacognitive skills - Lifelong learning \\
Moderate & Significant & 1.516 & -0.270 & Academic vitality - Study approaches \\
Weak & Not significant & 0.059 & 0.015 & Academic vitality - Lifelong learning \\
Weak & Not significant & 0.401 & 0.059 & Study approaches- Lifelong learning \\
\hline
\end{tabular}




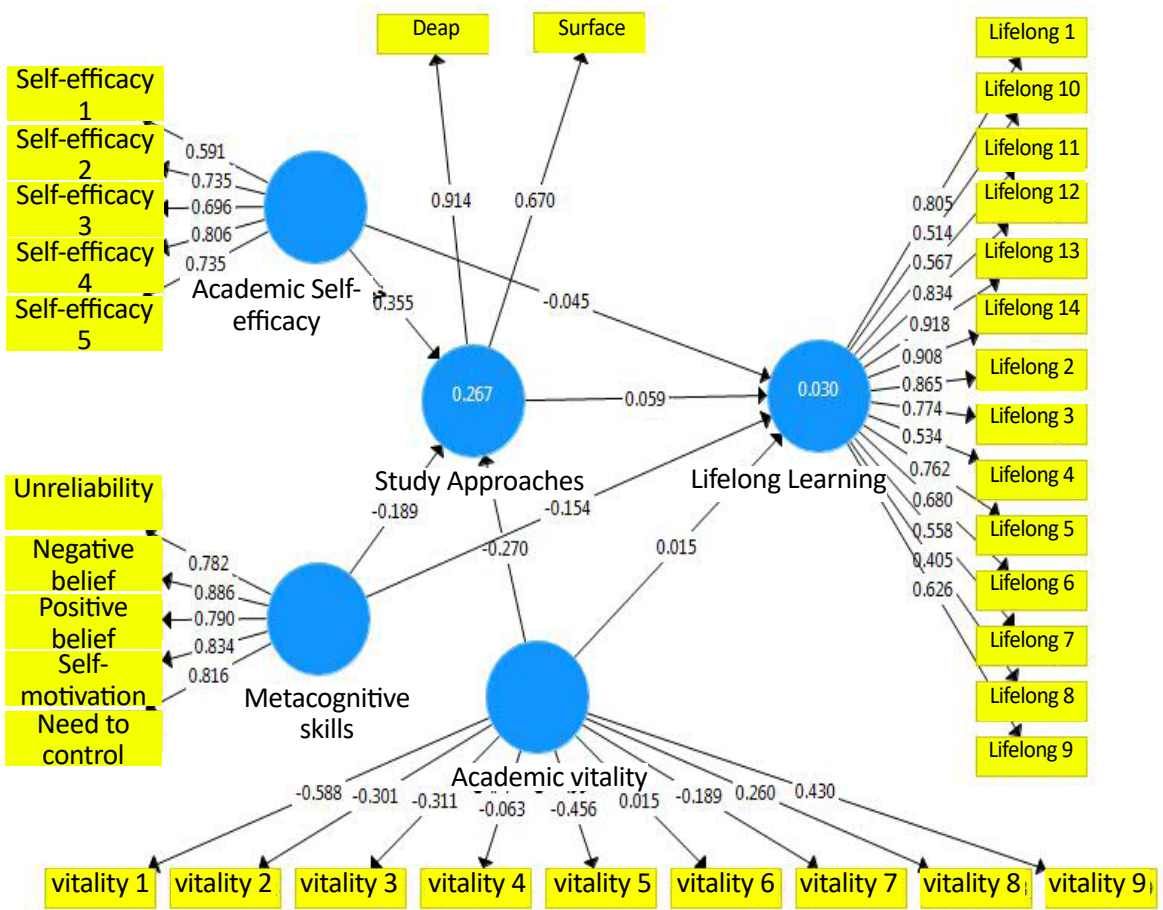

Figure 2. Route Coefficient Model

tion between these variables was justified because these variables result from several activities and actions and require one or several means. The study approach is certainly one of the most powerful and effective tools for achieving these goals.

The research main hypothesis claimed that the relationship between academic vitality, academic self-efficacy, and meta-cognitive skills and lifelong learning is significant through the mediating role of study approaches. The null hypothesis was rejected at a $95 \%$ confidence level, 0.002 significance level, and its comparison with 0.05 allowed error level. The main hypothesis was accepted. As a result, the relationship between academic vitality, academic self-efficacy, and cognitive skills and study strategies was significant with the moderating role of study approaches. Statistical findings in this study showed that many variables contributed to our tendency to learning after the end of a formal education program. In this regard, it should be stated that lifelong learning is also known as continuous learning, ongoing learning, and learning throughout life. It is not a normative concept but an organized multi-dimensional principle, which its vertical aspect involves the process of learning from birth to death, and the horizontal aspect encompasses the entire scope of individual and social life. It focuses on different learning environments, including family, society, school, and workplace.
This style of learning inevitably spreads out all senses and learning opportunities throughout life instead of focusing on uniform learning at a certain period and using learned materials throughout life. These provide opportunities to adapt to everyday changes and living possibilities to adapt to new changes in the best possible way. Lifelong learning is the key to provide continuous involvement in the progress of formal, informal, and free learning processes. This style of learning focuses on three different stages of life with three different goals: a. Cultural development that is dependent on the understanding, intellectual property, and conceptualization; b. Social development that is dependent on citizenship and social participation; and c. Professional development and employment that are dependent on production, job satisfaction, financial wellbeing, and economic stability. The model of t-test results are depicted in Figure 3.

\section{Conclusion}

Analysis of statistical data showed a significant relationship between the research variables and lifelong learning. In general, the results of this research are consistent with the results of the studies conducted by Cooke et al. [24], Cohen et al. [25], Ang et al. [26], Martin and Marsh [27], Martin [7], Lane and Lane [28], Jakaboski and Dimbo [29], Merati [30], Varzdar [31], Gervand et al. [32], Karimi Ghartmani [33], and Naghsh and Ghazi Tabatabai [34]. 
The effects of variables, such as gender, age, the field of study, and academic grade on lifelong learning were not important in this research. Therefore, these variables were not mentioned due to the large statistical analysis. Because the author intended to use the results of this study in future studies, the research was not limited to raw data. The statistical population consisted of students of the Payame Noor University of Kangavar and could be generalized to all students. Because lifelong learning, study approaches, academic vitality, academic self-efficacy, and metacognitive strategies were studied in this research and the sample size was small, the generalization of the results to the entire population is risky. Limitations of the study were as follows: A. Some students were not willing to complete the questionnaires; B. Several academic staff and personnel neglected the necessity of practical research in universities; C. A large number of research questionnaires was administered simultaneously with other questionnaires; D. Students of Payame Noor University are not always present in the university and the author could not access them easily due to specific education systems of these universities.

\section{Ethical Considerations}

\section{Compliance with ethical guidelines}

This study was approved by the Ethics Committee of the University of Payame Noor (Code: 03/25/J/1053).

\section{Funding}

The paper was extracted from the MA thesis of the first/ author, Payame Noor University, Tehran.

\section{Authors' contributions}

All authors equally contributed to preparing this article.

\section{Conflict of interest}

The authors declared no conflict of interest.

\section{References}

[1] Merati A. [Fundamentals of Educational Technology (Persian)]. Arak: Navaye Danesh; 2017. http://opac.nlai.ir/ opac-prod/search/briefListSearch.do?command=FULL_VI EW\&id $=7518955 \&$ pageStatus $=1 \&$ sortKeyValue1=sortkey title\&sortKeyValue2=sortkey_author
[2] Karami B, Allah Karami A, Hashemi N. [Effectiveness of teaching cognitive and metacognitive strategies on creativity, motivation for progress and academic self-concept (Persian)]. J Innov Creat Humanit. 2014; 2(4):121-40. http://journal.bpj.ir/

[3] Salehi S. [Study of the relationship between parents' lifestyles and creativity and academic achievement of their children (Persian)] [MSc. thesis]. Tehran: Islamic Azad university Science and Research Tehran; 2015.

[4] Lotfabadi H. [Psychology of growth, adolescence, youth and adult (Persian)]. Tehran: SAMT; 2016. https://samta.samt. ac.ir/content/13292/

[5] Hashemi E, Yazdanbakhsh K. Relativistic resiliency with high school students in high school in Ilam city. Mashhad: Second National Conference on Psychology; 2013.

[6] Seyf A. [Modern educational psychology (Persian)]. Tehran: Doran; 2016. https://www.adinehbook.com/gp/product/6006208213

[7] Syah Sayari N. Learning disabilities. Tehran: Modaber; 2008. https://www.gisoom.com/book/1444614/

[8] Samani S, Jokar B, Sahragard N. [Effects of resilience on mental health and life satisfaction (Persian)]. Iran J Psychiatry Clin Psychol. 2007; 13(3):290-5. http://ijpcp.iums.ac.ir/ article-1-275-en.html

[9] Abedi A. [Learn how to learn (cognitive and metacognitive learning skills) (Persian)]. Esfahan: Bartarin Andisheh; 2011 https://www.gisoom.com/book/1678540//

[10] Putwain DW, Connors L, Symes W, Douglas-Osborn E Is academic buoyancy anything more than adaptive coping? Anxiety, Stress Coping. 2012; 25(3):349-58. [DOI:10.1080/106] 5806.2011.582459] [PMID]

[11] Martin A. Academic buoyancy and academic outcomes Towards a further understanding of students with AttentionDeficit/Hyperactivity Disorder (ADHD), students without ADHD, and academic buoyancy itself. Br J Educ Psychol. 2014; 84(Pt 1):86-107 [DOI:10.1111/bjep.12007] [PMID]

[12] Richardson LD, Wolfe M. Principles and practice of informal education: Learning through life. London: Routledge 2004. https:// www.amazon.com/Principles-Practice-Informal-Education-Learning-ebook/dp/B000SH21H0

[13] Mashayekhi Dolatabadi M, Mohammadi M. [Resiliency and Spiritual Intelligence as the Conjugation of the predictors of academic self-efficacy in urban and rural students (Persian)]. J Psychol Sch. 2015; 3(2):205-25. http://jsp.uma.ac.ir/ article_211.html?lang=en

[14] Mashhadi A, Mohammadi M. Comparison of attachment styles in normal and delinquent adolescents. J Educ Stud Psychol. 2010; 10(3):127-40. [DOI: 10.22067/IJAP.V10I3.6958]

[15] Pouri H. Relationship between attachment to parents and classroom psychosocial class with academic achievement with the role of academic self-efficacy intermediation] [MSc thesis]. Shiraz: Faculty of Education and Psychology Shiraz University; 2014

[16] Taghipour A, Karimi FZ, Mousavi Bazzaz SM, Khosravi Anbaran Z, Abdollahi M. [Factor structure and reliability of the Persian version of the lifelong learning assessment tool (jeffSPLL-MS) (Persian)]. Iran J Med Educ. 2015; 14(11):988-97. http://ijme.mui.ac.ir/article-1-3199-fa.htm 
[17] Eggen PD, Kauchak DP. Educational psychology: Windows on classroom. $9^{\text {th }}$ ed. Upper Saddle River, N. J: Pearson Education; 2013. https://www.worldcat.org/title/educational-psychology-windows-on-classrooms/oclc/852641128

[18] Gage NL, Berliner DC. Educational psychology. $6^{\text {th }}$ ed. Boston: Houghton Mifflin; 1998. https://www.worldcat.org/ title/educational-psychology/oclc/38912303

[19] Porzour P. Determining relativity and resiliency with selfefficacy in students. Mashhad: Second National Conference on Psychology. 29 June 2013; Mahabad, Iran.

[20] Ababaf Z. [Comparing high school students cognitive and meta-cognitive strategies in learning, concerning their ability, field of study, and gender (Persian)]. Educ Innov. 2008;7(1):11950. http://noavaryedu.oerp.ir/article_78872.html?lang=en

[21] Aghazadeh M. [A guide to new teaching methods (Persian)]. Tehran: Pub Ayezh: 2012. https://www.gisoom.com/ book/1324116/\%DA

[22] Ghorchian N. [Theories of learning and meta-cognition theory in the process of teaching-learning (Persian)]. Tehran: Pub Tarbiyat; 2009. http://http://www.lib.ir/book/81379629 /\%D9\%86\%D8\%B8\%D8\%B1\%D9\%8A\%D9\%87\%D9\%87\%D8

[23] Abdous M. [The effect of teaching meta-cognitive strategies on creativity development in third grade high school students in Tehran (Persian)] [MSc. thesis]. Tehran: Al-Zahra University; 2002.

[24] Kwok O-M, Hughes JN, Luo W. Role of resilient personality on lower achieving first grade students' current and future achievement. J Sch Psychol. 2007; 45(1):61-82. [DOI:10.1016/j. jsp.2006.07.002] [PMID] [PMCID]

[25] Klassen RM, Krawchuk LL, Rajani S. Academic procrastination of undergraduates: Low self - efficacy to self - regulate predicts higher levels of procrastination. Contemp Educ Psychol. 2008; 33(4):915-31. [DOI:10.1016/j.cedpsych.2007.07.001]

[26] Ang RP, Huan VS. Academic expectation stress inventory: Development, factor analysis, reliability, and validity. EducPsychol Meas. 2006; 66(3):522-39. [DOI:10.1177/0013164405282461]

[27] Martin AJ, Marsh HW. Academic resilience and its psychological and educational correlations: A construct validity approach. Psychol Sch. 2006; 43(3):267-81. [DOI:10.1002/ pits.20149]

[28] Lane J, Lane AM. Self-efficacy and academic performance. Soc Behav Pers. 2001; 29(7):687-94. [DOI:10.2224/ sbp.2001.29.7.687]

[29] Jakubowski TG, Dembo MH. The relationship of self-effica$\mathrm{cy}$, identity style, and stage of change on academic self-regulation. J Coll Read Learn. 2004; 35(1):7-24. [DOI:10.1080/107901 95.2004.10850165]

[30] Merati A. Investigating the relationship between self-efficacy and cognitive flexibility. Proceedings of the symposium on new personality and life. Sanandaj: National Conference on Psychology. September 2015; Sanandaj, Iran. www.iausdj.ac.ir

[31] Varzdar Z. [The effect of metacognitive strategies on the academic achievement of primary school students in mathematical education in Islamshahr (Persian)] [MSc. thesis]. Tehran: Allameh Tabatabai University, Faculty of Psychology; 2011.
[32] Geravand H, Kareshki H, Ahanchian MR. [Relationship between research self-efficacy and research performance in students of Mashhad University of Medical Sciences (Persian)]. Iran J Med Educ. 2014; 14(1):41-51. http://ijme.mui. ac.ir/article-1-2928-fa.html

[33] Karimi ghartamani M. [The study of the relationship between academic self-esteem with self-perception and metacognition in high school students in Isfahan (Persian)] [MSc. thesis]. Tehran: Allameh Tabatabai University; 2013.

[34] Naghsh Z, Ghazi Tababaee M, Ali Tarkhan R. [The role of the structural pattern of self-efficacy relationship, perceived usefulness and academic achievement: The role of mediating self-discipline learning (Persian)]. Adv Cogn Sci. 2011; 12(4):36-44. http:/ /icssjournal.ir/article-1-178-fa.htm 